\title{
Tuberculosis Treatment and Drug Regimens
}

\author{
Giovanni Sotgiu ${ }^{1}$, Rosella Centis ${ }^{2}$, Lia D'ambrosioº ${ }^{2}$, and Giovanni Battista Migliori ${ }^{2}$ \\ ${ }^{1}$ Clinical Epidemiology and Medical Statistics Unit, Department of Biomedical Sciences, University \\ of Sassari, Research, Medical Education and Professional Development Unit, AOU Sassari 07100, Italy \\ ${ }^{2}$ World Health Organization Collaborating Centre for Tuberculosis and Lung Diseases, Fondazione \\ S. Maugeri, Care and Research Institute, Tradate 21049, Italy \\ Correspondence: gbmigliori@fsm.it
}

Tuberculosis is an airborne infectious disease treated with combination therapeutic regimens. Adherence to long-term antituberculosis therapy is crucial for maintaining adequate blood drug level. The emergence and spread of drug-resistant Mycobacterium tuberculosis strains are mainly favored by the inadequate medical management of the patients. The therapeutic approach for drug-resistant tuberculosis is cumbersome, because of the poor, expensive, less-effective, and toxic alternatives to the first-line drugs. New antituberculosis drugs (bedaquiline and delamanid) have been recently approved by the health authorities, but they cannot represent the definitive solution to the clinical management of drug-resistant tuberculosis forms, particularly in intermediate economy settings where the prevalence of drug resistance is high (China, India, and former Soviet Union countries). New research and development activities are urgently needed. Public health policies are required to preserve the new and old therapeutic options.

M edical treatment of tuberculosis, together with correct diagnosis, represents a cornerstone in the management and control of tuberculosis. It is relevant from a clinical and public health perspective, as tuberculosis is a serious contagious airborne disease.

Antibiotic treatment, reducing the bacterial load in the lungs, can be helpful to reduce the probability of transmission, along with other public health measures, such as isolation and cough etiquette.

The dramatic change of the epidemiological scenario during the last two decades, as a consequence of the increased incidence of the tuberculosis/HIV (human immunodeficiency virus) coinfection and of drug-resistant forms of tuberculosis, however, significantly complicated the clinical and public health management of the patients and of their contacts.

Currently, clinicians and public health specialists are facing daily problems related to the prescription of less effective and toxic secondline drugs, with frequent pharmacological interactions with antiretroviral drugs or medicines used to treat other comorbidities.

\section{TUBERCULOSIS THERAPY: HISTORY AND RATIONALE}

Tuberculosis is an ancient disease; nevertheless, effective drugs were not available for centuries. The preantibiotic therapy was initially repre-

Editors: Stefan H.E. Kaufmann, Eric J. Rubin, and Alimuddin Zumla

Additional Perspectives on Tuberculosis available at www.perspectivesinmedicine.org

Copyright (C) 2015 Cold Spring Harbor Laboratory Press; all rights reserved; doi: 10.1101/cshperspect.a017822

Cite this article as Cold Spring Harb Perspect Med 2015;5:a017822 
G. Sotgiu et al.

sented by isolation in sanatoria to reduce the probability of Mycobacterium tuberculosis transmission to healthy contacts, with rest, adequate nutrition, and sunlight exposure; then, the surgical approach represented the gold standard, after Carlo Forlanini's discovery of the beneficial effects of the artificially induced pneumothorax in 1927 (Rosenblatt 1973; Sakula 1983; Dheda and Migliori 2012).

Only after the discovery of the etiological agent by Robert Koch in 1882 and the identification of the antibacterial activity of penicillin by Alexander Fleming did new experimental activities focused on the evaluation of the efficacy of natural and chemical compounds in animals start (Goldsworthy and McFarlane 2002; Daniel 2006).

The first experimental evidence of the potential efficacy of new antituberculosis drugs was obtained in 1940 when a dapsone-derivative compound, known as promin, was administered to a sample of guinea pigs. However, that sulfonamide was never given to humans (Barry 1964; World Health Organization 2004; Migliori et al. 2011; Sotgiu et al. 2013).

A different destiny awaited streptomycin, a natural substance isolated from Streptomyces griseus, which proved its efficacy in animals and then in humans. In 1944, Schatz and Waksman stated that the drug could be prescribed for the treatment of tuberculosis as a consequence of its bactericidal activity. In 1946, the United Kingdom Medical Research Council Tuberculosis Unit showed its short-term 6-mo efficacy in terms of mortality reduction (i.e., from $27 \%$ to $7 \%$ ). However, after $5 \mathrm{yr}$, no differences were found between those exposed and not exposed to streptomycin as a consequence of the acquired antibiotic resistance (Table 1) (Schatz et al. 1944; Hinshaw and Feldman 1945; Wassersug 1946; Fox et al. 1954, 1999; World Health Organization 2004).

Four years later, the discovery of streptomycin, a new synthetic drug, called para-aminosalicylic acid (PAS), was presented as an alternative drug for the treatment of tuberculosis.

Following the poor results of the monotherapy, in 1952, the first regimen based on the combination of streptomycin, PAS, and isonia-
Table 1. Antituberculosis drugs

\begin{tabular}{|c|c|}
\hline Drug & Mean daily dosage \\
\hline Isoniazid & $5 \mathrm{mg} / \mathrm{kg}$ \\
\hline Rifampicin & $10 \mathrm{mg} / \mathrm{kg}$ \\
\hline Ethambutol & $15-25 \mathrm{mg} / \mathrm{kg}$ \\
\hline Pyrazinamide & $30-40 \mathrm{mg} / \mathrm{kg}$ \\
\hline Streptomycin & $15-20 \mathrm{mg} / \mathrm{kg}$ \\
\hline Amikacin & $15-20 \mathrm{mg} / \mathrm{kg}$ \\
\hline Kanamycin & $15-20 \mathrm{mg} / \mathrm{kg}$ \\
\hline Capreomycin & $15-20 \mathrm{mg} / \mathrm{kg}$ \\
\hline Ofloxacin & $800 \mathrm{mg}$ \\
\hline Ciprofloxacin & $1000 \mathrm{mg}$ \\
\hline Gatifloxacin & $400 \mathrm{mg}$ \\
\hline Moxifloxacin & $400 \mathrm{mg}$ \\
\hline Levofloxacin & $1000 \mathrm{mg}$ \\
\hline Ethionamide & $15-20 \mathrm{mg} / \mathrm{kg}$ \\
\hline Prothionamide & $15-20 \mathrm{mg} / \mathrm{kg}$ \\
\hline Cycloserine & $500-1000 \mathrm{mg}$ \\
\hline $\begin{array}{l}\text { Para-aminosalicylic } \\
\text { acid }\end{array}$ & $150 \mathrm{mg} / \mathrm{kg}$ \\
\hline Linezolid & $600 \mathrm{mg}$ \\
\hline Clofazimine & $200-300 \mathrm{mg}$ \\
\hline $\begin{array}{l}\text { Amoxicillin/ } \\
\text { clavulanate }\end{array}$ & $\begin{array}{c}875 / 125 \mathrm{mg} \text { BID or } \\
500 / 125 \mathrm{mg} \text { TID }\end{array}$ \\
\hline Clarithromycin & $1000 \mathrm{mg}$ \\
\hline Terizidone & $600-900 \mathrm{mg}$ \\
\hline Thiacetazone & $150 \mathrm{mg}$ \\
\hline Thioridazine & $75 \mathrm{mg}$ \\
\hline Bedaquiline & $\begin{array}{l}400 \mathrm{mg} \text { (for } 2 \mathrm{wk}) \\
200 \mathrm{mg} \text { TIW (for } 22 \mathrm{wk} \text { ) }\end{array}$ \\
\hline Delamanid & $200 \mathrm{mg}$ \\
\hline
\end{tabular}

BID, twice a day; TID, thrice a day; TIW, thrice a week.

zid was proposed. Sir John Crofton with the "Edinburgh method," characterized by the prescription of at least two drugs, showed the efficacy of the combination therapy (Crofton 1960, 1969, 2006; Fox et al. 1999; World Health Organization 2004; Migliori et al. 2011; Sotgiu et al. 2013).

In 1954, pyrazinamide was discovered, but at the prescribed dosages, the rate of hepatic toxicity was significantly high. Ethambutol and rifampicin were introduced in 1961 and 1963 , respectively. The duration of therapy varied from 1 to 2 yr. In 1970, trials on regimens including rifampicin showed good results with a therapy of 9 mo, whereas in 1974, the inclusion of rifampicin and pyrazinamide at low dosages demonstrated the efficacy of a 6-mo treat- 
ment (East African/British Medical Research Council 1974; Sensi 1983; Fox et al. 1999; Migliori et al. 2011; Sotgiu et al. 2013).

The Madras study started in India in 1956. It showed the efficacy of the ambulatory treatment and the crucial role of the directly observed treatment for the improvement of the patient's adherence (Table 2) (Dawson et al. 1966; Migliori et al. 2011; Sotgiu et al. 2013).

On the basis of the microbiological characteristics of M. tuberculosis (i.e., slow growth and dormancy of some of the bacilli belonging to the bacterial population), numerous scientific contributions showed the efficacy of a long-term and multidrug therapeutic approach to obtain a bacteriological eradication in pulmonary and extrapulmonary sites.

Other factors can contribute to the successful outcome of the antituberculosis therapy, including the chemical features of the infection site. An adequate combination of effective drugs can reduce the probability of failure, relapse, and selection of resistant strains. To achieve those clinical and public health outcomes, it is necessary to prescribe antituberculosis drugs with an adequate dosage, for a specific time of exposure, and whose efficacy has been proved in in vitro tests (i.e., drug-susceptibility testing). In particular, to avoid the emer-

Table 2. Historical steps of the antituberculosis treatment

\begin{tabular}{|c|c|}
\hline Year & Historical step \\
\hline 1940 & Use of promin in guinea pigs \\
\hline $1944-1946$ & Discovery of streptomycin \\
\hline 1948 & Discovery of para-aminosalicylic acid \\
\hline 1952 & $\begin{array}{l}\text { Streptomycin }+ \text { para-aminosalicylic } \\
\text { acid }+ \text { isoniazid }\end{array}$ \\
\hline 1954 & Discovery of pyrazinamide \\
\hline 1956 & Madras study \\
\hline 1961 & Discovery of ethambutol \\
\hline 1963 & Discovery of rifampicin \\
\hline 1970 & 9-mo rifampicin-containing regimens \\
\hline 1974 & $\begin{array}{l}\text { 6-mo rifampicin- and pyrazinamide- } \\
\text { containing regimens }\end{array}$ \\
\hline 2012 & $\begin{array}{l}\text { Food and Drug Administration } \\
\text { approval of bedaquiline }\end{array}$ \\
\hline 2013 & $\begin{array}{l}\text { Approval of delamanid by European } \\
\text { Regulatory authorities }\end{array}$ \\
\hline
\end{tabular}

gence of resistant strains, it is necessary to prescribe at least two effective drugs.

Duration of drug exposure is different according to the susceptibility of the isolated strains. In general, two different steps in the treatment of tuberculosis can be recognizedinitial (or bactericidal) phase and continuation (or sterilizing) phase. During the first step of treatment, mycobacteria with a high replication rate are killed, and, consequently, with the histological pulmonary restoration and the reduction of the inflammation process, symptoms and clinical signs resolve (clinical recovery). From a public health perspective, this phase is crucial because the treated patient becomes noninfectious and the probability of selection of drug-resistant strains decreases (it is directly correlated to the fast-growing bacteria). The continuation phase is oriented to the elimination of semidormant bacteria, whose size is significantly reduced if compared with that at the beginning of the antituberculosis therapy; this quantitative feature, related to the low replication rate, is associated with a low probability of emergence of drug-resistant mycobacteria. In cases of drug-susceptible tuberculosis, two potent medicines are sufficient (e.g., isoniazid and rifampicin) in this phase. On the other hand, the regimen prescribed during the initial phase is more complex: two bactericidal drugs (isoniazid with streptomycin or rifampicin), ethambutol to inhibit monoresistant strains and to reduce the mycobacterial burden, and pyrazinamide, whose action is mainly focused to the semidormant mycobacteria. The intensive phase has a duration of $4 \mathrm{mo}$, whereas the sterilizing phase has a duration of 2 mo.

On this basis, the choice of the antituberculosis drugs in the different phases is not random but is based on the epidemiology (e.g., resistance rate in a specific setting, probability of having been infected by a contact with drugresistant tuberculosis) and on the specificity of action of the antituberculosis drugs. The antituberculosis drug armamentarium is characterized by molecules with two main different mechanisms of action-bactericidal effect and sterilizing effect. The first one is crucial in the intensive phase and allows a relevant reduction 
G. Sotgiu et al.

of the bacterial load; the indirect consequence of this activity is the reduction of the probability of selecting drug-resistant strains. The most important drugs prescribed for that aim are isoniazid, pyrazinamide, rifampicin, and streptomycin. The sterilizing activity is relevant in the initial phase and in the continuation phase, but primarily in the continuation phase because it is oriented to kill mycobacteria in a dormancy state. Antituberculosis drugs deemed helpful in this phase are pyrazinamide and rifampicin.

These general principles are accepted worldwide, and the standardized regimens recommended by the World Health Organization in its guidelines have their roots in this biological rationale (World Health Organization 2004; Migliori et al. 2011; Sotgiu et al. 2013).

The World Health Organization classified antituberculosis drugs into five classes following several criteria, among them their efficacy and their chemical characteristics. The drugs usually prescribed for the drug-susceptible tuberculosis are included in the first class, whereas the drugs with unclear efficacy are included in the fifth class. In particular, the following drugs are integrated in the first class: ethambutol, isoniazid, pyrazinamide, and rifampicin. The second class includes amikacin, capreomycin, kanamycin, and streptomycin; old- and new-generation fluoroquinolones are included in the third class. The antituberculosis drugs in the fourth class are cycloserine, ethionamide, para-aminosalicylic acid, prothionamide, terizidone, and thioacetazone. The fifth class encompasses amoxicillin/clavulanate, clarithromycin, clofazimine, imipenem, and linezolid (World Health Organization 2010).

\section{TREATMENT OF DRUG-SUSCEPTIBLE TUBERCULOSIS (WORLD HEALTH ORGANIZATION 2010)}

Individuals diagnosed with a pulmonary form of tuberculosis, not exposed to antituberculosis drugs for $>1$ mo (i.e., "new cases" of tuberculosis), have to be treated for 6 mo. During the 2-mo intensive phase, patients should be administered a combined regimen includ- ing ethambutol, isoniazid, pyrazinamide, and rifampicin. Only isoniazid and rifampicin are prescribed during the 4-mo continuation phase.

Patients should take drugs daily to obtain a clinical and a microbiological cure; however, during the second phase of treatment, thrice per week is allowed, but, in that case, adherence is crucial to avoid reduction of the drugs' blood level and, consequently, the risk of emergence of drugs' resistances.

As mentioned above, a higher efficacy of antituberculosis regimens longer than 6 mo for individuals both with and without HIV infection was not shown; a different scenario has been found in the treatment of the latent tuberculosis infection, in which the duration of the treatment is longer in HIV-infected patients.

Microbiological monitoring of the efficacy of the prescribed regimen is mandatory; sputum smear and culture conversion should be evaluated, particularly at the end of the intensive and continuation phases of treatment.

Previously treated cases (i.e., previous course of antituberculosis drugs for $>1 \mathrm{mo}$ ) should be managed differently. To prescribe an effective regimen tailored on the phenotypic profile of the mycobacterial isolates, a rapid and conventional drug-susceptibility testing is required before the initiation of therapy. It is crucial to monitor the potential adverse events to avoid the interruption of the prescribed therapy (Table 3).

The World Health Organization recommends the prescription of an empiric regimen for those who are identified as relapsers or defaulters, in case of a low multidrug resistance prevalence-ethambutol, isoniazid, pyrazinamide, rifampicin, and streptomycin in the intensive phase, followed by ethambutol, isoniazid, pyrazinamide, and rifampicin for $30 \mathrm{~d}$; the last 5-mo phase is characterized by ethambutol, isoniazid, and rifampicin, for a total duration of 8 mo (Table 4).

It was clearly shown that the 6-mo regimen is practically $100 \%$ effective; after a follow-up period of $2 \mathrm{yr}$, the relapse rate can range from $0 \%$ to $7 \%$. Intermittent regimens proved a similar efficacy, with a slightly higher relapse rate at 
Table 3. Main adverse events of the antituberculosis drugs

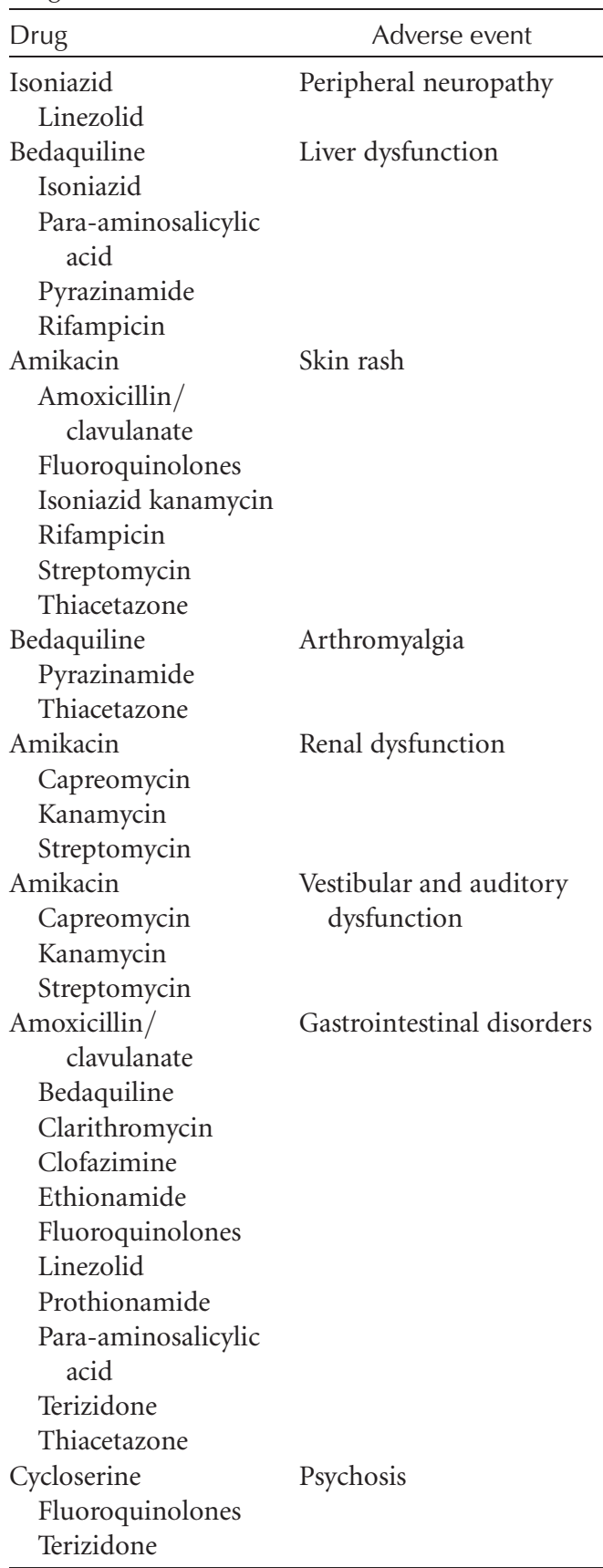

2 and $5 \mathrm{yr}$ and a lower proportion of adverse events (World Health Organization 2004).

Extrapulmonary tuberculosis is a paucibacillary disease, and therapeutic regimens are the same as those prescribed for the pulmonary forms. Severe extrapulmonary disease, characterized by the neurological, abdominal, bilateral pleural, pericardial, bone, or joint or systemic involvement, needs four drugs in the intensive phase and sometimes a treatment duration of 9 mo (e.g., in case of neurological involvement). In case of relevant inflammation, the prescription of steroids is recommended. However, the prognosis strictly depends on the precocity of the administration of the antituberculosis drugs (World Health Organization 2004).

\section{TREATMENT OF DRUG-RESISTANT TUBERCULOSIS}

The clinical and public health management of drug-resistant tuberculosis is complicated. The therapeutic approach, as well as the prognosis, is significantly associated with the resistance pattern (Falzon et al. 2011; World Health Organization 2011b).

It has been clearly shown that the multidrug resistance (i.e., the resistance in vitro to at least isoniazid and rifampicin) could represent a relevant clinical issue because of the poorest therapeutic armamentarium. The so-called second- and third-line antituberculosis drugs are less efficacious, more toxic, and more expensive than the first-line drugs.

It is straightforward that the adequate treatment of drug-resistant tuberculosis can prevent the emergence of new serious drug-resistant forms, which could have a worst prognosis and less alternative therapeutic options.

Furthermore, another relevant feature of an adequate and early treatment is the low probability of transmission of drug-resistant mycobacterial strains in a specific setting, such as a hospital or a community.

Nevertheless, to obtain a clinical and a microbiological cure, it is mandatory to treat individuals for a long period because of the lesser effectiveness of the second- and third-line drugs. The prolonged exposure to medicines, characterized by a poor safety and tolerability profile, reduces the adherence of the patient. This pathogenetic step could be crucial for the 


\section{G. Sotgiu et al.}
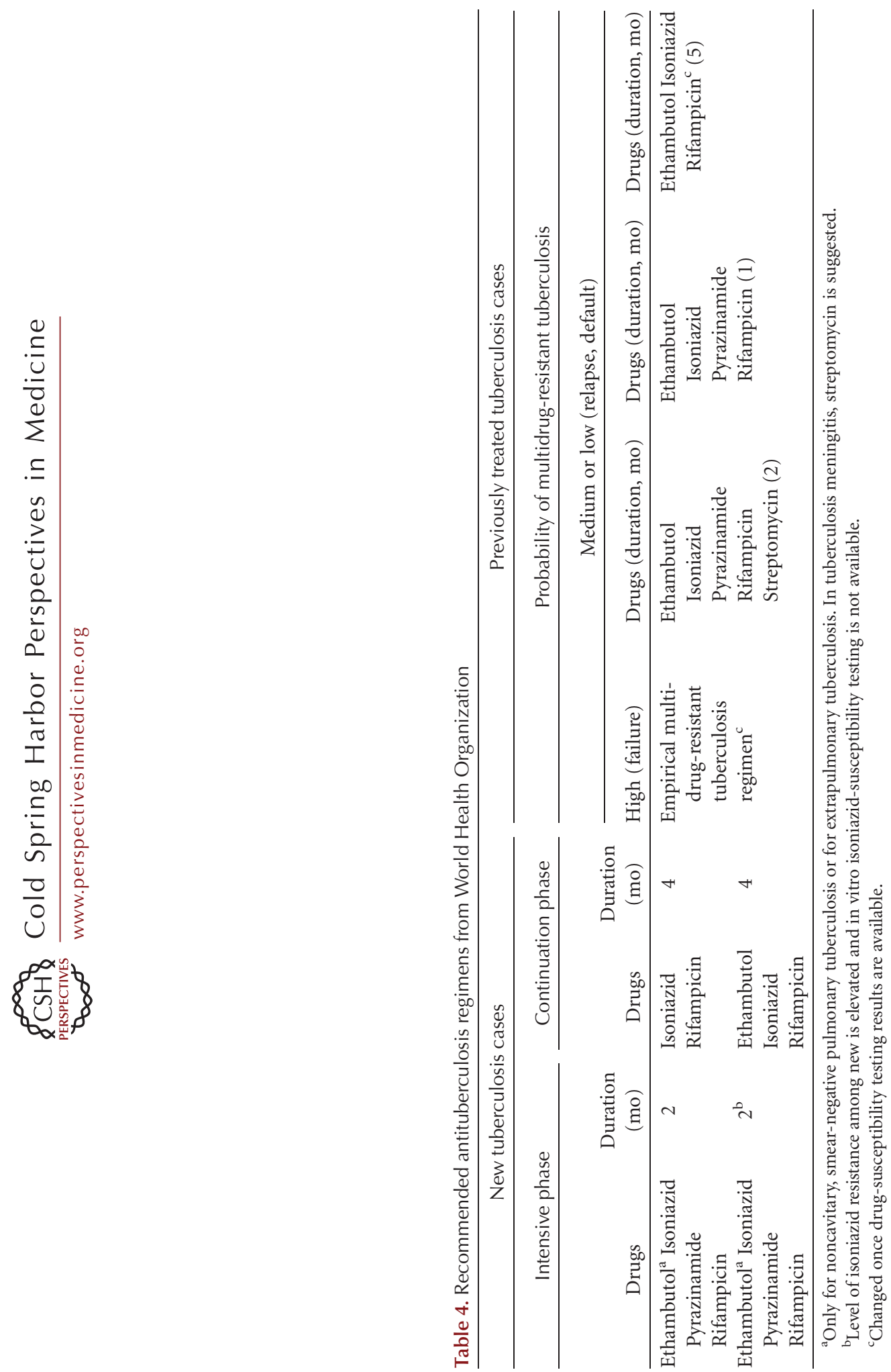
emergence of new drug-resistant mycobacterial strains and their spread in the community.

One of the most important points in the management of the drug-resistant strains is the prescription of an efficacious drug regimen, which should be based on the results of the drug-susceptibility testing. The current availability of rapid molecular tests, which can assess the resistances of mycobacterial strains to isoniazid and rifampicin, can allow the administration of an early tailored antituberculosis regimen. In particular, the World Health Organization recently approved an automated nucleic acid amplification test to diagnose tuberculosis disease and to assess mycobacterial resistance to rifampicin (Xpert MTB/RIF System). The rapid identification of a multidrug-resistant case can allow an immediate prescription of an empiric and specific antituberculosis drug regimen. This molecular method might avoid the administration of an inappropriate treatment and, consequently, indirectly favor the clinical recovery of patients and the reduction of their infectiousness (World Health Organization 2011a).

The World Health Organization suggests the prescription of at least four active drugs during the intensive phase. In particular, the backbone of the administered regimen should include pyrazinamide, one of the injectable second-line drugs (amikacin, capreomycin, or kanamycin), a new-generation fluoroquinolone, ethionamide (or prothionamide), and cycloserine (or PAS). Other drugs should be prescribed in case of resistances to one or more of the backbone drugs. The duration of the first phase of the treatment should depend on the culture conversion, but it should last at least 8 mo, whereas the duration of the second phase should be longer than $20 \mathrm{mo}$.

The World Health Organization guidelines issued in 2011 (WHO 2011b) showed significant differences if compared with those issued in 2008; in particular, the suggested duration of the intensive phase is longer (i.e., 8 vs. $6 \mathrm{mo}$ ), as well as the total duration of therapy (i.e., at least $20 \mathrm{mo}$ ). If feasible, pyrazinamide should be added up to a backbone regimen of four second-line antituberculosis drugs, in which ethionamide and new-generation fluoroquinolones are the preferred medicines. Furthermore, monthly monitoring of the culture conversion is relevant to assess the efficacy of the prescribed therapy (World Health Organization 2008).

New therapeutic options have been proposed in recent years for the management of the drug-resistant mycobacterial strains, including new molecules and drugs prescribed for other diseases.

Several drugs, approved for infectious diseases other than tuberculosis, showed in vitro and in vivo antimycobacterial activity; among them, imipenem-cilastatin, linezolid, and meropenem-clavulanate have had a relevant role in individuals with drug-resistant tuberculosis in the last few years. The new molecules recently approved or in the last clinical trial phases are bedaquiline (a new diarylquinoline, previously called TMC 207), delamanid (previously called OPC-67683), sutezolid (PNU 100480), and PA-824.

Bedaquiline and delamanid have recently received a marketing approval. Bedaquilinecontaining regimens increase by 12 times the probability of culture conversion in multidrug-resistant tuberculosis cases and prevent the emergence of further resistances to the drugs included in the backbone regimens. It reduces the time to culture conversion in the first $6 \mathrm{mo}$ of exposure (hazard ratio: 2.3). The safety and tolerability profile is good if compared with other antituberculosis drugs (i.e., acne, bilateral hearing impairment, extremity and noncardiac chest pain). However, the frequency of nausea was significantly higher during some clinical trials if compared with that in the control group (Diacon et al. 2009, 2012a,b, 2013; Willyard 2012; Mahajan 2013; World Health Organization 2013b).

Delamanid-containing regimens showed a short- and long-term efficacy in terms of culture conversion. The positive microbiological features are associated with the relevant improvement of a strong epidemiological indicator-like mortality; the proportion of individuals who died after a $\geq 6$-mo exposure to delamanid was $1 \%$ versus $8 \%$ in those not exposed or with a short-term exposure. The percentage 
G. Sotgiu et al.

of individuals who culture-converted at 2 mo was about $45 \%$ versus nearly $30 \%$ in the control group. The most important adverse event that occurred in patients exposed to this novel nitroimidazole was QT prolongation, although not associated to relevant cardiac events (Diacon et al. 2011; Gler et al. 2012; Skripconoka et al. 2013).

Other new promising drugs are currently being tested in the phase II and III clinical trials. In particular, sutezolid, belonging to the same chemical family of linezolid, showed its ability in the reduction of the colony forming units (Shaw and Barbachyn 2011; Wallis et al. 2012). The early bactericidal activity showed by PA-824, a new nitroimidazo-oxazine, was superior to that of bedaquiline in the first clinical trials (Diacon et al. 2012a,b; Migliori and Sotgiu 2012).

Antibiotics licensed for bacterial infections other than tuberculosis proved their efficacy in the treatment of the multidrug-resistant and extensively drug-resistant tuberculosis cases.

Linezolid is efficacious but is characterized by several hematological side effects (anemia and/or leucopenia and/or thrombocytopenia), peripheral nervous system problems, and gastrointestinal toxicity. However, it has been proved that the therapeutic monitoring of its blood levels (TDM) can allow a dosage adjustment, followed by the reduction of the probability of occurrence of adverse events. Several pharmacokinetic studies showed that a 600-mg dosage has the best cost/benefit ratio. TDM was helpful in understanding the best dosage to be administered to patients on the basis of the blood drug concentration. It was clear that a daily dosage of $1200 \mathrm{mg}$ is toxic if compared with a $600-\mathrm{mg}$ dosage. On the other hand, a 300-mg daily dosage is less efficacious (Migliori et al. 2009; Sotgiu et al. 2009, 2012; Alffenaar et al. 2010; Koh et al. 2012; Srivastava et al. 2013).

Meropenem-clavulanate and cotrimoxazole showed their efficacy in some observational studies. The former favored sputum smear and culture conversion in $>80 \%$ of the multidrugresistant tuberculosis cases $(88 \%$ and $84 \%$, respectively, in a case-control study) and was associated with an optimal safety profile (De Lorenzo et al. 2013). The latter was evaluated in vitro and in a few cases, and its efficacy needs to be proved in experimental, controlled studies (Forgacs et al. 2009; Huang et al. 2012; Vilchèze and Jacobs 2012). New experimental clinical trials are needed to assess the clinical profile of the new therapeutic options (Grosset et al. 2012; Pontali et al. 2013).

The management of individuals with multidrug-resistant tuberculosis and HIV infection requires the involvement of tuberculosis/ HIV specialists. Anti-HIV drugs should be prescribed within $8 \mathrm{mo}$ from the first administration of the antituberculosis drugs. The pill burden is relevant and the adherence of the patients can be significantly affected; furthermore, the toxicity linked to the pharmacological interactions can contribute to reduce the compliance of the patients. In particular, the severity of the hepatic, gastrointestinal, hematological, renal, and central and peripheral nervous system toxicity could interrupt the treatment (Table 5).

A recent systematic review, enrolling $217 \mathrm{pa}$ tients, whose CD4 cell counts were $<200 \mu \mathrm{L}$ in the majority of cases, showed that individuals exposed to antiretrovirals were more likely to survive (hazard ratio of 0.38 ) and have a longer median time to death (i.e., 37 mo vs. 11 mo among those not exposed to antiretrovirals). Furthermore, the prescription of antiretroviral drugs was associated with a higher probability of cure (hazard ratio, 3.4). It was proved that the level of immunodeficiency and the mycobacterial resistance pattern do not influence the above-mentioned risks (Arentz et al. 2012).

The concomitant prescription of anti-HIV and antituberculosis drugs does not depend on the severity of the immunodeficiency and then on the CD4 cell counts.

\section{ADHERENCE TO ANTITUBERCULOSIS THERAPY}

The efficacy of the combination regimens described above will determine, in addition to bacteriological conversion, a subjective improvement of the patient's clinical conditions. The latter feature may anticipate the microbiological conversion and could be paradoxically dangerous from an individual and a public 
Table 5. Main adverse events of the antituberculosis drugs and of the antiretrovirals

\begin{tabular}{|c|c|c|}
\hline Antituberculosis drugs & Antiretroviral drugs & Adverse event \\
\hline $\begin{array}{l}\text { Isoniazid } \\
\text { Linezolid }\end{array}$ & $\begin{array}{l}\text { Didanosine } \\
\text { Stavudine }\end{array}$ & Peripheral neuropathy \\
\hline Bedaquiline & Efavirenz & Liver dysfunction \\
\hline Isoniazid & Etravirine & \\
\hline Para-aminosalicylic acid & Maraviroc & \\
\hline Pyrazinamide & Nevirapine & \\
\hline Rifampicin & $\begin{array}{l}\text { Ritonavir/protease } \\
\text { inhibitors }\end{array}$ & \\
\hline Amikacin & Abacavir & Skin rash \\
\hline Amoxicillin/clavulanate & Efavirenz & \\
\hline Fluoroquinolones & Etravirine & \\
\hline Isoniazid kanamycin & Nevirapine & \\
\hline \multicolumn{3}{|l|}{ Rifampicin } \\
\hline \multicolumn{3}{|l|}{ Streptomycin } \\
\hline \multicolumn{3}{|l|}{ Thiacetazone } \\
\hline Bedaquiline & - & Arthromyalgia \\
\hline \multicolumn{3}{|l|}{ Pyrazinamide } \\
\hline \multicolumn{3}{|l|}{ Thiacetazone } \\
\hline Amikacin & Indinavir & Renal dysfuction \\
\hline Capreomycin & Tenofovir & \\
\hline \multicolumn{3}{|l|}{ Kanamycin } \\
\hline \multicolumn{3}{|l|}{ Streptomycin } \\
\hline Amikacin & - & Vestibular and auditory dysfunction \\
\hline \multicolumn{3}{|l|}{ Capreomycin } \\
\hline \multicolumn{3}{|l|}{ Kanamycin } \\
\hline \multicolumn{3}{|l|}{ Streptomycin } \\
\hline Amoxicillin/clavulanate & Didanosine & Gastrointestinal disorders \\
\hline Bedaquiline clarithromycin & Protease inhibitors & \\
\hline Clofazimine & Stavudine & \\
\hline $\begin{array}{l}\text { Ethionamide fluoroquinolones } \\
\text { linezolid }\end{array}$ & Zidovudine & \\
\hline \multicolumn{3}{|l|}{ Prothionamide } \\
\hline \multicolumn{3}{|l|}{ Para-aminosalicylic acid } \\
\hline \multicolumn{3}{|l|}{ Terizidone } \\
\hline \multicolumn{3}{|l|}{ Thiacetazone } \\
\hline Cycloserine fluoroquinolones terizidone & Efavirenz & Psychosis \\
\hline
\end{tabular}

Data modified from Arentz et al. 2012.

health perspective; patients feeling better might decide to interrupt their treatment.

Several approaches have been proposed to increase patient's adherence. One of the most important is the so-called DOT (i.e., directly observed therapy). The patient takes the prescribed therapy in the presence of a healthcare worker (physician or nurse), a social worker, or another person involved in agreement with the local tuberculosis program. The direct observation avoids all the problems associated with self-administration, including compliance with the dosages and time of administration affecting the pharmacokinetic curve of the drugs. In addition, DOT allows rapid management of adverse events related to the drug intake.

Another important tool to enhance adherence is represented by the fixed-dose combination of the antituberculosis drugs. They were 
G. Sotgiu et al.

introduced in clinical practice at the end of the 1980s, and several advantages were immediately recognized: easy management for the national tuberculosis program and for health staff not fully familiar with antituberculosis drugs and reduced probability of emergence of drug resistances because of the improved patient's adherence. The main disadvantages, intrinsically related to the fixed dose, are the risk of a nonadequate blood level (rare, and limited to patients characterized by a poor intestinal absorption or by a rapid metabolism) and the difficulty in attributing an adverse event to a specific drug.

Another strategic therapeutic approach to improve adherence is represented by the intermittent regimens, whose efficacy was shown in 1964 in Chennai, India. Antituberculosis drugs are administered at intervals of $>1 \mathrm{~d}$. The relapse rate is $8 \%$ after a follow-up of 2 yr (World Health Organization 2004).

An important role to increase adherence can be played by incentives and enablers (money, food, incentives for transportation, etc.), particularly in resource-limited countries. Poor patients living in rural areas can lose their job and their daily salary because of the medical visits in far urban settings. National tuberculosis programs should identify the geographical areas or the social groups where these nonmedical interventions could be crucial in improving adherence (Tuberculosis Coalition for Technical Assistance 2009).

Last but not least, when health education is adequately provided by health services to the patients and their families, adherence tends to improve.

\section{CONCLUDING REMARKS}

The current therapeutic management of drugsusceptible and drug-resistant strains needs to be further improved. The available regimens are characterized by a relevant pill burden, long duration, variable efficacy, safety, and tolerability. The overall treatment success rate is below the recommended World Health Organization proportion of $85 \%$, and, consequently, the drug resistance level increases.
The World Health Organization estimates that a suboptimal proportion of multidrug-resistant cases is presently diagnosed and treated. In $2010,48 \%$ of the detected multidrug-resistant tuberculosis cases were successfully treated. Only 34 countries obtained a treatment success rate $\geq 75 \%$ (World Health Organization 2013a). Even in tuberculosis reference centers, the proportion of treatment success in multidrug-resistant cases does not exceed 50\%.

Although the adherence, efficacy, safety, and tolerability profile of the newly available drugs (delamanid and bedaquiline, in particular) appear to be promising, we cannot predict, as of today, their long-term efficacy and the affordability of their use in resource-limited settings. Further research efforts are necessary to identify the potentialities of the new drugs and to understand better how to use them in combination regimens.

These new regimens are ideally able to treat tuberculosis sustained by both drug-susceptible and drug-resistant strains without interfering with antiretroviral drugs, thus allowing a more effective approach against HIV-infected cases.

The new approach adopted to test different drug combinations in parallel can improve the current situation, giving new insights in a shorter period of time.

New research and development activities are requested, along with a preservation of the current therapeutic options. Training and educational activities focused on the rationale use of the antituberculosis drugs are necessary to avoid the dramatic increase of the drug-resistant forms.

National and local public health programs should issue guidance, based on the local epidemiology, to prevent inappropriate management of the new and old antibiotics, as to ensure that all cases of tuberculosis diagnosed and correctly treated, complete their treatment. The risk is to loose the new drugs in much less than the time necessary to develop them.

\section{REFERENCES}

Alffenaar JW, van Altena R, Harmelink IM, Filguera P, Molenaar E, Wessels AM, van Soolingen D, Kosterink 
JG, Uges DR, van der Werf TS. 2010. Comparison of the pharmacokinetics of two dosage regimens of linezolid in multidrug-resistant and extensively drug-resistant tuberculosis patients. Clin Pharmacokinet 49: 559-565.

Arentz M, Pavlinac P, Kimerling ME, Horne DJ, Falzon D, Schünemann HJ, Royce S, Dheda K, Walson JL, ART study group. 2012. Use of anti-retroviral therapy in tuberculosis patients on second-line anti-TB regimens: A systematic review. PLoS ONE 7: e47370.

Barry VC. 1964. Development of the chemotherapeutic agent for tuberculosis. In Chemotherapy of tuberculosis (ed. Barry VC). Butterworths, London.

Crofton J. 1960. Tuberculosis undefeated. Br Med J 2: 679687.

Crofton J. 1969. Some principles in the chemotherapy of bacterial infections. Br Med J 2: 137-141.

Crofton J. 2006. The MRC randomized trial of streptomycin and its legacy: A view from the clinical front line. $J R S o c$ Med 99: 531-534.

Daniel TM. 2006. The history of tuberculosis. Respir Med 100: $1862-1870$.

Dawson JJY, Devadatta S, Fox W, Radhakrishna S, Ramakrishnan CV, Somasundaram PR, Stott H, Tripathy SP, Velu S. 1966. A 5-year study of patients with pulmonary tuberculosis in a concurrent comparison of home and sanatorium treatment for one year with isoniazid plus PAS. Bull World Health Organ 34: 533-551.

De Lorenzo S, Alffenaar JW, Sotgiu G, Centis R, D'Ambrosio L, Tiberi S, Bolhuis MS, van Altena R, Viggiani P, Piana A, et al. 2013. Efficacy and safety of meropenem-clavulanate added to linezolid-containing regimens in the treatment of MDR-/XDR-TB. Eur Respir J 41: 1386-1392.

Dheda K, Migliori GB. 2012. The global rise of extensively drug-resistant tuberculosis: Is the time to bring back sanatoria now overdue? Lancet 379: 773-775.

Diacon AH, Pym A, Grobusch M, Patientia R, Rustomjee R, Page-Shipp L, Pistorius C, Krause R, Bogoshi M, Churchyard G, et al. 2009. The diarylquinoline TMC207 for multidrug-resistant tuberculosis. $N$ Engl $J$ Med 360: 2397-2405.

Diacon AH, Dawson R, Hanekom M, Narunsky K, Venter A, Hittel N, Geiter LJ, Wells CD, Paccaly AJ, Donald PR. 2011. Early bactericidal activity of delamanid (OPC67683) in smear-positive pulmonary tuberculosis patients. Int J Tuberc Lung Dis 15: 949-954.

Diacon AH, Dawson R, von Groote-Bidlingmaier F, Symons G, Venter A, Donald PR, van Niekerk C, Everitt D, Winter H, Becker P, et al. 2012a. 14-day bactericidal activity of PA-824, bedaquiline, pyrazinamide, and moxifloxacin combinations: A randomised trial. Lancet 380: 986-993.

Diacon AH, Donald PR, Pym A, Grobusch M, Patientia RF, Mahanyele R, Bantubani N, Narasimooloo R, De Marez T, van Heeswijk R, et al. 2012b. Randomized pilot trial of eight weeks of bedaquiline (TMC207) treatment for multidrug-resistant tuberculosis: Long-term outcome, tolerability, and effect on emergence of drug resistance. Antimicrob Agents Chemother 56: 3271-3276.

Diacon AH, Dawson R, du Bois J, Narunsky K, Venter A, Donald PR, van Niekerk C, Erondu N, Ginsberg AM, Becker P, et al. 2012c. Phase II dose-ranging trial of the early bactericidal activity of PA-824. Antimicrob Agents Chemother 56: 3027-3031.
Diacon AH, Dawson R, Von Groote-Bidlingmaier F, Symons G, Venter A, Donald PR, Conradie A, Erondu N, Ginsberg AM, Egizi E, et al. 2013. Randomized dose-ranging study of the 14-day early bactericidal activity of bedaquiline (TMC207) in patients with sputum microscopy smear-positive pulmonary tuberculosis. Antimicrob Agents Chemother 57: 2199-2203.

East African/British Medical Research Council. 1974. Controlled clinical treatment of short course (6 months) regime of chemotherapy for treatment of pulmonary tuberculosis. Third report. Lancet 2: 237-248.

Falzon D, Jaramillo E, Schünemann HJ, Arentz M, Bauer M, Bayona J, Blanc L, Caminero JA, Daley CL, Duncombe C, et al. 2011. WHO guidelines for the programmatic management of drug-resistant tuberculosis: 2011 update. Eur Respir J 38: 516-528.

Forgacs P, Wengenack NL, Hall L, Zimmerman SK, Silverman ML, Roberts GD. 2009. Tuberculosis and trimethoprim-sulfamethoxazole. Antimicrob Agents Chemother 53: 4789-4793.

Fox W, Sutherland I, Daniels M. 1954. A five-year assessment of patients in a controlled trial of streptomycin in pulmonary tuberculosis: Report to the Tuberculosis Chemotherapy Trials Committee of the Medical Research Council. QJM 91: 347-366.

Fox W, Ellard GA, Mitchison DA. 1999. Studies on the treatment of tuberculosis undertaken by the British Medical Research Council tuberculosis units, 1946-1986, with relevant subsequent publications. Int J Tuberc Lung Dis 3: S231-S279.

Gler MT, Skripconoka V, Sanchez-Garavito E, Xiao H, Cabrera-Rivero JL, Vargas-Vasquez DE, Gao M, Awad M, Park SK, Shim TS, et al. 2012. Delamanid for multidrug-resistant pulmonary tuberculosis. $N$ Engl J Med 366: 2151-2160.

Goldsworthy PD, McFarlane AC. 2002. Howard Florey, Alexander Fleming and the fairy tale of penicillin. Med $J$ Aust 176: 176-178.

Grosset JH, Singer TG, Bishai WR. 2012. New drugs for the treatment of tuberculosis: Hope and reality. Int $J$ Tuberc Lung Dis 16: 1005-1014.

Hinshaw HC, Feldman WH. 1945. Streptomycin in the treatment of clinical tuberculosis; a preliminary report. Proc Staff Meet Mayo Clin 20: 313-318.

Huang TS, Kunin CM, Yan BS, Chen YS, Lee SS, Syu W Jr. 2012. Susceptibility of Mycobacterium tuberculosis to sulfamethoxazole, trimethoprim and their combination over a 12 year period in Taiwan. J Antimicrob Chemother 67: 633-637.

Koh WJ, Kang YR, Jeon K, Kwon OJ, Lyu J, Kim WS, Shim TS. 2012. Daily $300 \mathrm{mg}$ dose of linezolid for multidrugresistant and extensively drug-resistant tuberculosis: Updated analysis of 51 patients. J Antimicrob Chemother 67: 1503-1507.

Mahajan R. 2013. Bedaquiline: First FDA-approved tuberculosis drug in 40 years. Int J Appl Basic Med Res 3: 1-2.

Migliori GB, Sotgiu G. 2012. Treatment of tuberculosis: Have we turned the corner? Lancet 380: 955-957.

Migliori GB, Eker B, Richardson MD, Sotgiu G, Zellweger JP, Skrahina A, Ortmann J, Girardi E, Hoffmann H, Besozzi G, et al. 2009. A retrospective TBNETassessment 
G. Sotgiu et al.

of linezolid safety, tolerability and efficacy in multidrugresistant tuberculosis. Eur Respir J 34: 387-393.

Migliori GB, Sotgiu G, Centis R, Grzemska M, Falzon D, Getahun H, Raviglione MC. 2011. Antituberculosis therapy and current global guidelines. In Current \& emerging diagnostics, therapeutics \& vaccines for tuberculosis (ed. Kaufmann SHE), pp. 42-63. Future Medicine, London.

Pontali E, Matteelli A, Migliori GB. 2013. Drug-resistant tuberculosis. Curr Opin Pulm Med 19: 266-272.

Rosenblatt MB. 1973. Pulmonary tuberculosis: Evolution of modern therapy. Bull NY Acad Med 49: 163-196.

Sakula A. 1983. Carlo Forlanini, inventor of artificial pneumothorax for treatment of pulmonary tuberculosis. Tho$\operatorname{rax} 38: 326-332$.

Schatz A, Bugie E, Waksman SA. 1944. Streptomycin, a substance exhibiting antibiotic activity against Gram-positive and Gram-negative bacteria. ProcSoc Exp Biol Med 55: 66-69.

Shaw KJ, Barbachyn MR. 2011. The oxazolidinones: Past, present, and future. Ann N Y Acad Sci 1241: 48-70.

Sensi P. 1983. History of the development of rifampicin. Rev Infect Dis 5: 402-406.

Skripconoka V, Danilovits M, Pehme L, Tomson T, Skenders G, Kummik T, Cirule A, Leimane V, Kurve A, Levina K, et al. 2013. Delamanid improves outcomes and reduces mortality in multidrug-resistant tuberculosis. Eur Respir J 41: 1393-1400.

Sotgiu G, Lange C, Richardson MD, Matteelli A, Centis R, Eker B, Guenther G, Spanevello A, Migliori GB; TBNET. 2009. Comment on: Daily $300 \mathrm{mg}$ dose of linezolid for the treatment of intractable multidrug-resistant and extensively drug-resistant tuberculosis. J Antimicrob Chemother 64: 879-883.

Sotgiu G, Centis R, D’Ambrosio L, Alffenaar JW, Anger HA, Caminero JA, Castiglia P, De Lorenzo S, Ferrara G, Koh WJ, et al. 2012. Efficacy, safety and tolerability of linezolid containing regimens in treating MDR-TB and XDR-TB: Systematic review and meta-analysis. Eur Respir J 40: $1430-1442$.

Sotgiu G, Centis R, D’Ambrosio L, Migliori GB. 2013. Medical treatment of pulmonary tuberculosis. Eur Respir Society Monograph 61: 11-19.

Srivastava S, Peloquin CA, Sotgiu G, Migliori GB. 2013. Therapeutic drug management: Is it the future of multi- drug-resistant tuberculosis treatment? Eur Respir J 42: 1449-1453.

Tuberculosis Coalition for Technical Assistance. International Standards for Tuberculosis Care (ISTC), 2nd ed. 2009. Tuberculosis Coalition for Technical Assistance, The Hague.

Vilchèze C, Jacobs WR Jr. 2012. The combination of sulfamethoxazole, trimethoprim, and isoniazid or rifampin is bactericidal and prevents the emergence of drug resistance in Mycobacterium tuberculosis. Antimicrob Agents Chemother 56: 5142-5148.

Wallis RS, Jakubiec W, Mitton-Fry M, Ladutko L, Campbell S, Paige D, Silvia A, Miller PF. 2012. Rapid evaluation in whole blood culture of regimens for XDR-TB containing PNU-100480 (sutezolid), TMC207, PA-824, SQ109, and pyrazinamide. PLoS ONE 7: e30479.

Wassersug JD. 1946. Pulmonary tuberculosis. N Engl J Med 235: $220-229$.

Willyard C. 2012. Race heats up for first-to-market drugs for resistant tuberculosis. Nat Med 18: 1157.

World Health Organization. 2004. Toman's tuberculosis: Case detection, treatment and monitoring, second edition. WHO, Geneva.

World Health Organization. 2008. Guidelines for the programmatic management of drug-resistant tuberculosis. Emergency update 2008. WHO/HTM/TB/2008.402. WHO, Geneva.

World Health Organization. 2010. The treatment of tuberculosis guidelines. Document WHO/HTM/TB/2009.420. WHO, Geneva.

World Health Organization. 2011a. Automated real-time nucleic acid amplification technology for rapid and simultaneous detection of tuberculosis and rifampicin resistance: Xpert MTB/RIF system. Policy statement. WHO/HTM/TB/2011.4. WHO, Geneva.

World Health Organization. 2011b. Guidelines for the programmatic management of drug-resistant tuberculosis 2011 update. WHO/HTM/TB/2011.6. WHO, Geneva.

World Health Organization. 2013a. Global tuberculosis report 2013. WHO/HTM/TB/2013.11. WHO, Geneva.

World Health Organization. 2013b. The use of bedaquiline in the treatment of multidrug-resistant tuberculosis: Interim policy guidance. WHO, Geneva. 


\section{$\&_{\mathrm{CSH}}^{\infty} \&$ Cold Spring Harbor

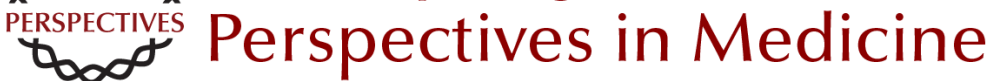

\section{Tuberculosis Treatment and Drug Regimens}

Giovanni Sotgiu, Rosella Centis, Lia D'ambrosio and Giovanni Battista Migliori

Cold Spring Harb Perspect Med 2015; doi: 10.1101/cshperspect.a017822 originally published online January 8, 2015

\section{Subject Collection Tuberculosis}

Transmission and Institutional Infection Control of Tuberculosis Edward A. Nardell

Innate and Adaptive Cellular Immune Responses

to Mycobacterium tuberculosis Infection Katrin D. Mayer-Barber and Daniel L. Barber

Tuberculosis Comorbidity with Communicable and Noncommunicable Diseases

Matthew Bates, Ben J. Marais and Alimuddin Zumla

Host-Directed Therapies for Tuberculosis David M. Tobin

Immunity and Immunopathology in the

Tuberculous Granuloma

Antonio J. Pagán and Lalita Ramakrishnan

Tuberculosis Drug Development: History and

Evolution of the Mechanism-Based Paradigm? Sumit Chakraborty and Kyu Y. Rhee

Genetic Approaches to Facilitate Antibacterial

Drug Development

Dirk Schnappinger

The Tuberculosis Drug Discovery and

Development Pipeline and Emerging Drug Targets

Khisimuzi Mdluli, Takushi Kaneko and Anna Upton
Clinical Aspects of Adult Tuberculosis Robert Loddenkemper, Marc Lipman and Alimuddin Zumla

Advances in Diagnostic Assays for Tuberculosis Stephen D. Lawn

Diagnosis and Management of Latent

Tuberculosis Infection

Laura Muñoz, Helen R. Stagg and Ibrahim

Abubakar

Mycobacterial Growth

Iria Uhía, Kerstin J. Williams, Vahid Shahrezaei, et al.

Multidrug-Resistant Tuberculosis and Extensively

Drug-Resistant Tuberculosis

Kwonjune J. Seung, Salmaan Keshavjee and Michael L. Rich

The Mycobacterial Cell Wall--Peptidoglycan and

Arabinogalactan Luke J. Alderwick, James Harrison, Georgina S. Lloyd, et al.

Tuberculosis and HIV Coinfection Judith Bruchfeld, Margarida Correia-Neves and Gunilla Källenius

Imaging in Tuberculosis Jamshed B. Bomanji, Narainder Gupta, Parveen Gulati, et al.

For additional articles in this collection, see http://perspectivesinmedicine.cshlp.org/cgi/collection/ 